MÉNDEZ RuBIO, Antonio (2016).

Comunicación musical y cultura popular.

Una introducción crítica. Valencia: Tirant Humanidades.

"Con la música... a otra parte" es el refrán con el que Antonio Méndez Rubio abre la introducción a su estudio Comunicación musical y cultura popular. Una introducción crítica, publicado por Tirant Humanidades en el año 2016. Como sabemos, los refranes son, en parte, transmisores del conocimiento popular y nos permiten ahondar en nuestro imaginario colectivo; de esta manera, el autor reflexiona a partir de esta paremia del lugar, o el no-lugar, de la música en la sociedad, advirtiendo sobre la concepción generalizada de esta como elemento bello pero carente de utilidad y que, a la vez, es imprescindible en nuestra experiencia diaria como seres humanos.

Pero, "con la música... a otra parte": ¿dónde?, ¿por qué?, ¿qué música debe irse?, ¿quién decide a qué otra parte debe irse?, ¿a quién le molesta y quién la utiliza?, ¿con qué fin y con qué medios?, ¿qué relación existe entre música y poder?, ¿cómo se convierte la música popular en un fenómeno masivo?, ¿qué papel cumple la industria musical en este proceso y qué estrategias utiliza?, ¿en qué contexto tiene lugar el surgimiento y desarrollo de un estilo?, ¿dónde quedan los orígenes subalternos de ciertos estilos tras su utilización comercial masiva?, ¿cómo se produce el ascenso y la aceptación de una expresión musical popular a la categoría de alta cultura? Bien, un simple refrán genera un amplio campo de interrogantes en el que tanto los amantes de la música como los investigadores encontrarán las claves para su estudio en la presente obra.

Comunicación musical y cultura popular viene a abrir el diálogo sobre la comunicación musical y el estudio en torno a la relación música-sociedad, es decir, la música entendida como práctica social que interactúa con actores tanto en el plano económico como en el político y mediático. Es por esto que la obra no solo pretende centrarse en la música como lenguaje o arte, sino entenderla como parte de la cultura con el fin de investigar en los contextos sociales de surgimiento y expansión de las distintas expresiones musicales y la relación que estas han tenido con la industria musical que la emplea para vehicular sus intereses económicos y políticos.

Desde una perspectiva múltiple, que conjuga tanto el plano teórico como el crítico y también el histórico, Méndez Rubio aborda el análisis a lo largo de tres grandes bloques que la estructuran: en primer lugar, en "Cultura y música popular" hallamos una aproximación teórica sobre aspectos clave del lenguaje, la comunicación musical, la industria musical y la música popular, que otorga las herramientas necesarias para centrarse los en estilos concretos que se desarrollan más adelante; en segundo lugar, en "Música rock como cultura" encontramos un análisis tanto histórico como cultural del rock desde sus orígenes hasta su crisis, su relación con otros estilos, las principales figuras y el papel que jugó la industria musical en su difusión; por último, "Nuevas músicas globales" extenderá su aproximación a los nuevos estilos musicales que tras el ocaso del rock se han establecido en el siglo XXI como, por ejemplo, la música electrónica, el hip-hop o la world music.

A continuación dividiremos nuestro análisis en los tres grandes bloques que configuran el estudio y nos centraremos en los aspectos más relevantes que el autor destaca en cada apartado.

\section{CULTURA Y MÚSICA POPULAR}

En la la introducción teórica, el autor nos aproxima a los conceptos clave de la teoría musical y a la perspectiva de las relaciones entre cultura popular e industria. En primer lugar, el autor nos ofrece su visión sobre la música como forma de comunicación, por la que no podemos entender a esta de manera aislada o técnica, sino que debemos tener en cuenta el contexto social en el que se produce, para advertir las relaciones que se establecen entre música y poder. Méndez Rubio destaca que la música 
refleja las condiciones históricas en las que se produce y que los diversos estilos traslucen los mecanismos y efectos de poder, como, por ejemplo, en el caso de la música ambiental utilizada como vía de fomento del consumo y la productividad.

En este sentido, el autor señala que en la modernidad occidental se consolidó el estatus de alta cultura de la música clásica, que determinó que las disciplinas especializadas la fijaran como objeto de estudio, dejando de lado al resto de músicas de carácter popular. De este modo, se produce lo que Méndez Rubio denomina la separación entre lo clásico y lo popular, estableciendo a la música clásica como dispositivo de control elitista que mostrará las diferencias entre clases sociales y que reafirmará los roles característicos de la sociedad de masas, en la que una minoría privilegiada se establece como emisora de un mensaje dirigido a la mayoría que no pertenece a los poderes fácticos. El autor señala casos de utilización elitista de la música clásica no extraídos únicamente de la corriente romántica del XIX, sino que también indica cómo en el siglo XX, tanto la publicidad como las producciones de Hollywood de los años 30 y 40 la usaron como signo de prestigio y autoridad.

Debemos destacar el acompañamiento del desarrollo teórico de esta parte con ejemplos concretos y de alcance popular; así pues, cuando el autor reflexiona, a partir de la concepción nietzscheana de lo apolíneo y lo dionisíaco, sobre la canción popular, entendida como espacio donde se conjugan lenguaje (la palabra) y música dando lugar a la articulación entre "instinto y realidad" y entre "cuerpo y mundo", el autor justifica sus reflexiones a partir de ejemplos como la canción "There goes my baby" de The Drifters o "Wave of mutilation" de The Pixies, en la que analiza la progresión musical de los acordes en relación a la temática autodestructiva de la composición.

A continuación, el autor se centra en el estudio de la condición musical a partir del estudio de los vínculos entre la música, el lenguaje, signos y significado, el ruido y el contexto social. Méndez Rubio destaca que la música y el lenguaje establecen una relación de reciprocidad en la que, de manera inevitable, influyen unas determinadas circunstancias sociales; a partir de las consideraciones de Wagner, Darwin o Rousseau ratifica la naturaleza biológica de la relación entre música y lenguaje, con la que se podría considerar a la música como una precondición de la palabra, por lo que la música se establecerá como una evidente forma de comunicación social.

El autor plantea las relaciones entre signo musical y significado, observando las trabas que supone un análisis semiótico de la condición musical, debido a las dificultades que implica la cuestión de la referencialidad en la música, de modo que las nociones tanto de significado como de signo deberían someterse a una revisión crítica. Méndez plantea que el signo musical actuaría de manera semejante a la función poética del lenguaje, formulada por R. Jakobson, por al desplazamiento signo-realidad que lo abriría a la relación de reciprocidad entre signos.

Ante la complejidad que implica la determinación de un signo o símbolo que represente el hecho musical, el autor señala que la condición musical es una condición dialógica, en la que interactúan la música, el lenguaje y la cultura, por lo que será necesario contemplar la música como práctica social y atender a las relaciones de poder que se plasman en ella. El autor defiende aunar el análisis en el plano formal y en el social, con el fin de hallar en la música el componente de institucionalización con el que se ha utilizado; también destaca, a partir de las reflexiones de Attali y Delleuze y Guattari, su capacidad subversiva al no atarse la condición musical a las convenciones simbólicas básicas de los códigos, como, por ejemplo, muestra en la utilización del ruido en la condición musical. El ruido cuestionaría y permitiría el desmontaje de los códigos y de las estrategias de poder de la industria, pues como señala Méndez las músicas que se alejan de la codificación son desterradas por parte de las industrias musicales y sus objetivos comerciales. 
Como hemos indicado, no podemos aislar la música de las condiciones en las que se produce, por este motivo el autor introduce un apartado dedicado a la industria musical, como factor de tipo económico y comercial. De este modo, señala tres etapas históricas que nos permitirán observar su evolución: en primer lugar, los inicios (1890-1950), en los que aparecen las primeras discográficas y a partir de la década de los 40 encontramos un crecimiento marcado, entre otros factores, por la aparición de la frecuencia modulada; el surgimiento del Jukebox, del vinilo de 33rpm y y de los inicios de la televisión comercial. En segundo lugar, encontramos "la edad de oro" (1950-1990), en la que tiene lugar la consolidación de la industria que extenderá sus raíces hasta la actualidad, en la que destacan factores como la grabación en estéreo o la aparición del cassete y del walk-man. Sin embargo, el autor hace hincapié en los factores mediáticos que dieron lugar a lo que llama un continuum musical, como la aparición de la radiofórmula y de la televisión musical en 1981 con MTV. Por último, la tercera etapa es la que denomina como "la era digital", desde la década de los 90 hasta la actualidad, en la que se produce la consolidación de la industria y su crisis; el autor destaca procesos de tipo empresarial como las fusiones entre grandes empresas como Warner Music, EMI, Sony, Universal y BMG; la implantación del CD a partir de los 90 y el desarrollo del MP3 en el nuevo milenio con el auge de internet.

Es relevante contemplar el apartado que el autor dedica al estudio de la relación de la industria y la cultura. Señala que al tratarse la música de una forma de comunicación vital, la industria ve en ello una oportunidad de negocio, con la que tratará de operar en la música y en la cultura aplicando las leyes de la oferta y la demanda con las que se rige el mercado, haciendo uso de los mass media en la construcción de consumidores según sus parámetros. Sin embargo, el autor destaca la importancia de un cambio de sentido en esta relación que vaya de la cultura a la industria, donde la industria dependerá de la cultura popular y de los cambios en los contextos sociales. Así pues, en la actualidad, la llamada revolución digital está produciendo un cambio tanto en las formas musicales como en las relaciones con la industria, que deberá aprender a moverse en este periodo evolutivo, atendiendo a plataformas streaming, Youtube o las descargas.

Llegados a este punto, el autor se centra en el estudio de la música popular contemporánea y parte del estudio del lugar de la música en la construcción política de la sociedad; para ello, nos remite a las consideraciones tanto de Platón como de Kant, que consideraban que debía someterse a una regulación pues podría poner en peligro la convivencia; pero, en contraposición, nos remite a la postura de Nietzsche, contrario a esta visión coercitiva de la música. A partir del siglo XX y la crítica de tipo marxista encontramos el estudio de la música y los mecanismos de control del poder, con lo que llegamos al concepto de estandarización de Adorno, en el que se advierten las presiones de la industria y los intereses capitalistas, que el autor utiliza para analizar el caso del jazz y el blues. De esta manera, el Méndez Rubio introduce el concepto de música popular contemporánea, como espacio amplio en el que entran en contacto factores musicales y extramusicales.

Méndez Rubio destaca la conveniencia de no confundir popular con masivo, planteando visualizar la relación entre ambos conceptos con la banda de Moebius, en la que se escenifican los movimientos y las presiones entre ambas. En todo momento, Méndez Rubio destaca la importancia de comprender la cultura popular como práctica social heterológica, abierta a la participación; a partir de la modernidad occidental con la que se instauró la música clásica como alta cultura, las músicas populares se vieron sometidas a presiones que buscaban un control y homogeneización que borraran las diferencias de clase, una de las estrategias de masificación de la industria. El autor ofrece como clave para interpretar estos movimientos de abajo a arriba un esquema triangular en el que en la base se encontrarían las músicas 
populares subalternas, en el centro hallaríamos una franja de mediación en la que la industria actuaría como filtro de reconocimiento de las músicas subalternas hacia el estatus de alta cultura, ubicándolas en la cúspide de la pirámide.

Así pues, el autor ejemplifica las negociaciones entre músicas de carácter subalterno y la industria musical a través del blues y el jazz, músicas de origen subalterno que surgieron en un determinado contexto social de discriminación étnica y que se convirtieron en vía de expresión de grupos oprimidos; estas músicas posteriormente se cruzaron con otros estilos de naturaleza distinta y se integraron en los canales comerciales.

\section{MÚSICA ROCK COMO CULTURA}

En la segunda parte del libro, encontramos un estudio particularizado del rock and roll, en el que se examinan las condiciones sociales en las que surge y se desarrolla; el papel de la industria en su difusión y su constitución como cultura. Para realizar este análisis decir histórico-cultural se centra en el estudio por décadas de los principales acontecimientos y figuras de este fenómeno desde su surgimiento, en los años 50, hasta su declive, en las postrimerías del siglo XX.

Debemos entender el rock no solo como un estilo musical, sino como un fenómeno cultural en el que se entrecruzan factores de tipo social, histórico y cultural y en el que se advierte la negociación y tensión entre cultura popular e industria. De este modo, en el rock hallamos el punto de confluencia entre las culturas subalternas de las que se nutre y las condiciones y estrategias impuestas por la industria musical en su conversión en producto masivo.

Así pues, en el rock hallamos influencias de músicas populares tanto de origen subalterno como aceptadas social y comercialmente; en este sentido, debemos destacar que la cuestión racial es un factor determinante, el autor divide las influencias en música popular negra, entre la que se encuentra el blues y el r'n'b; música popular blanca, donde encontramos el country y el rockabilly; y, por último, la música melódica, un estilo basado en la estandarización de las músicas populares y en la finalidad comercial dirigida a un público blanco $\mathrm{y}$, mayoritariamente de clase media.

Gracias a esta división de influencias, el autor nos indica la importancia de la cuestión racial que subyace al fenómeno del rock y que sugiere denominar etnicidad; en una sociedad donde tuvo lugar la esclavitud y la segregación racial era todo un hecho, el hombre negro era conducido a una invisibilidad forzada o su representación en el imaginario popular se limitaba al estereotipo; de esta manera, el autor sugiere que el componente de negritud del rock fue sometido a una segregación, del que este estilo es muestra, por parte de los medios de la industria, en la que se daban cita los conflictos sociales de la época.

En el libro autobiográfico que Bruce Springsteen ha publicado recientemente, Born to Run, encontramos una anécdota significativa que enraíza con este estudio y con la que el cantante relata cómo él y la conservadora sociedad norteamericana se introdujeron de pleno en el rock and roll: la aparición en el año 1956 de Elvis Presley en el Ed Sullivan Show. Estas son sus palabras:

¡iLA REVOLUCIÓN HA SIDO TELEVISADA!!(...) Setenta millones de estadounidenses fueron expuestos aquella noche a aquel terremoto humano que sacudía las caderas. La temerosa nación fue protegida de sí misma por las cámaras de la CBS, a quienes se había ordenado que encuadrasen al "chico" solo de cintura para arriba (...) Un precursor de un vasto cambio cultural, una nueva clase de hombre, un ser humano moderno, que difuminaba las barreras raciales, los géneros sexuales y... ¡SE DIVERTía! (Springsteen, 2016: 54-56).

Estas palabras son reveladoras, pues condensan los principales rasgos que Méndez Rubio atriubye al fenómeno rock. En primer lugar: un cambio cultural; en segundo lugar; la música popular como expresión del cuerpo, de lo sexual, de lo dionisíaco; en tercer lugar, la voluntad de los medios de "normalizar" y 
"estandarizar" el fenómeno tratando de desviar la atención del componente sexual en busca de la aceptación de la opinión pública configurada dentro de una visión conservadora; en cuarto lugar, las barreras raciales de la sociedad y el uso que el rock hace de estilos procedentes de la cultura popular y subalterna negra; por último, el componente juvenil y de rebeldía que, en parte, despierta el rock.

Así pues, Méndez Rubio toma la figura de Elvis Presley en su análisis como un espacio de cruce en el que se entrelazan diversos estilos que van desde el country hasta el blues y que pone en escena la sexualidad y la rebeldía. Sin embargo, a través del estudio de diferentes apariciones televisivas de Elvis, Méndez Rubio advierte el moldeado que la industria ejerce en la difusión de un fenómeno que bebe de expresiones subalternas y que debe pasar a ser aceptado por la opinión pública y a convertirse en masivo. En su primera aparición encontramos a un Elvis que despierta el erotismo y el desenfreno, como relata Springsteen; en las siguientes apariciones, las televisiones nos muestran una versión más moderada, sin enfocar sus movimientos de cadera y convirtiéndolo con el paso del tiempo en la imagen de cantante melódico, tipo crooner. De este modo, con la conversión de Elvis Presley en tótem del rock and roll se procede al blanqueado de su figura y también de la cultura, no solo en cuanto a la búsqueda de la neutralización de la imagen de rebeldía y sexualidad, sino que también en cuanto a la segregación racial, por lo que se produce su inserción en el mainstream.

La década de los 60, se caracteriza por la crisis de la industria norteamericana y el declive de los principales exponentes del rock and roll por sus conflictos legales, de manera que el foco se establece en Gran Bretaña a partir de dos de los grupos que marcarán las nuevas líneas de la música popular hasta la actualidad: The Beatles y The Rolling Stones, quienes se presentaban como una confluencia entre la música popular negra y blanca; los primeros marcaron una tendencia más inclinada hacia el pop-rock, con influencias de grupos pop negro como The
Marvelettes o Isley Brothers; los segundos, en cambio, se aproximaron al blues y al $r^{\prime} n ' b$, con influencias como Muddy Waters o Elmore James y que en su último disco publicado en 2016 Blue \& Lonesome, recuperan de manera específica. En este sentido, es importante la construcción que los medios de comunicación hicieron de ambos grupos: por un lado, The Beatles con una imagen más afable y benévola y, por otro, The Rolling Stones con una apariencia más provocadora y arrogante.

Sin embargo, los 60 no se centran únicamente en la aparición de estas dos bandas, sino que, como apunta Méndez, se da la eclosión de la música folk, el soul y el rock de vanguardia. En un contexto de creciente capitalismo, de tensiones sociales de tipo racial y el contraste entre las ansias de libertad de una juventud frente a las imposiciones morales de una sociedad conservadora, surgieron movimientos sociales estudiantiles y en favor de los derechos civiles, los cuales encontrarían en la música una vía de expresión. Como señala el autor, el rock, que atravesaba un momento de declive rendido a las estrategias mercantiles, comenzó a nutrirse de estas nuevas formas musicales en busca de su regeneración y adaptación a los nuevos tiempos.

En la década de los 70, Méndez indica que nos encontramos ante los inicios de la explosión, que ejemplifica a partir del estallido final a ritmo de Pink Floyd de la película Zabriskie Point de Antonioni, que simbolizaría lo que describe como el colapso derivado de las grandes crisis industriales y económicas del 1973 y del 1976 y de la situación del rock, ubicado en el centro de la cultura masiva por parte de la industria y su acercamiento al pop. Pero la eclosión no fue solo de sistema, sino que también de nuevas músicas de carácter subalterno que nacen como resistencia y reflejo del colapso, como, por ejemplo, el punk, el reggae, el disco el heavy.

Así pues, destaca el caso del rock progresivo, vertiente procedente de la psicodelia y vanguardia del rock de los últimos 60, que en esta década entra en lo que el autor señala como 
una controversia, ya que a la vez emplea la experimentación creativa y que, a su vez, se incorpora dentro del circuito masivo, del mismo modo que en el esquema triangular negociaría en el espacio medio para incorporarse a la alta cultura. En esta época, se produce de nuevo la tensión entre músicas populares e industria, en la que los estilos emergentes y subculturales negociarán con una industria que querrá utilizarlos con fines comerciales y convertirlos en masivos.

El caso del punk es, quizá, uno de los más notables en cuanto a la tendencia de análisis propuesta por Méndez, pues como expresión artística es indisoluble del contexto urbano e industrial occidental en el que emerge, donde las crisis económicas y el desempleo generaron una sensación de hastío frente a los nuevos modelos sociales que se instauraban y que, a la vez, se encontraba con la inevitable relación con una industria en un momento de auge que trataría de incorporarlo dentro del circuito masivo. Así pues, el punk se convierte en una expresión crítica que encontraría en la música, la estética y la actitud una vía para expresar su rabia y su tendencia autodestructiva; para ello, rehuirá de las composiciones y melodías del rock progresivo empleando, como señala Méndez, unos acordes básicos y la tendencia al ruido con una voz que roza el grito, como forma de expresión de ese hartazgo generacional y de ruptura con los modelos comerciales en los que se había inmerso el rock. Su relación con la industria y sus tentativas de convertirlo en moda socavarán la capacidad de subversión de este movimiento.

En la década de los 80, el autor indica que nos hallamos en una época de consumo desenfrenado, en el que se dan factores como la expansión de la tarjeta de crédito, el consumo televisivo y la adquisición de productos tecnológicos. En esta etapa, la industria mostrará sus capacidades y estrategias de mercado a partir de la difusión del videoclip y de la consagración del pop como estilo hegemónico, lo que caracterizará a la crisis del rock en este periodo finisecular. Méndez Rubio destaca un factor clave: la aparición de la televisión musical con la creación del canal MTV en el 1981, hecho que marcará el sometimiento de lo musical a la imagen, al vídeo, y a la espectacularidad, convirtiéndose prácticamente en un producto publicitario o que, al menos, sigue sus estrategias. Como muestra, el autor analiza el fenómeno del cineclip a partir de películas como Dirty Dancing, Flashdance o Fame; en el caso del videoclip, se centra en Madonna como artista representativa de la masificación del pop, Méndez Rubio utiliza como ejemplo el clip de la canción "Open your Heart”, donde se hace visible la conversión de la mujer en objeto (sujeto pasivo) de la mirada masculina (sujeto activo), lo cual será una constante en el mundo del clip musical que ha llegado hasta nuestros días y que es una muestra de la sociedad patriarcal en la que vivimos.

En los dos últimos decenios del siglo XX, el rock se ve inmerso en una crisis en la que se someterá a las dinámicas de la industria musical, a la hegemonía del pop y a los cambios en el mundo tecnológico a partir de la aparición de nuevos formatos, en especial, con el auge de internet. Así pues, el autor destaca que sobrevive a caballo entre la relevancia adquirida por grandes bandas como U2, R.E.M o Guns'n'Roses y por otro lado, con la proliferación a partir de los años 90 de nuevos géneros como el grunge o el brit-pop.

\section{NUEVAS MÚSICAS GLOBALES}

La última parte del libro extiende la visión más allá del rock y se centra en lo que denomina como nuevas músicas globales, en las que el fenómeno de la globalización económica y cultural y la expansión e imposición del pop en los medios de comunicación han contribuido a su desarrollo; en este proceso encontramos como factores determinantes las estrategias empleadas por medios como MTV o la factoría Disney, que han contribuido a la expansión a nivel mundial del pop, del que el autor destaca que su vertiente comercial es la que mejor la puede definir, es decir, su estatus como producto.

Debemos destacar las consideraciones que realiza Méndez Rubio sobre el papel de la crisis 
económica de 2008 en la industria musical y en la reformulación del pop a partir de tres características como son el predominio de la canción sobre el álbum, debido a cuestiones económicas de producción y de difusión mediante descargas en internet; el papel predominante de la mujer bajo una mirada erotizada que la objetualiza; y la aparición de grupos sociales subalternos en las producciones.

En este apartado, Méndez analiza los casos de tres estilos: la world music, el hip-hop y la música electrónica. Sobre la world music nos indica que es un tipo de música en el que interactúa lo local y lo global, como consecuencia directa de los procesos globalizadores en los que se incorporan a los circuitos de difusión músicas procedentes de culturas fuera del ámbito occidental o bien de estratos sociales marginales o suburbiales. Como muestra de este tipo de música, el autor se detiene en el caso del mestizaje rock empleado por Manu Chao y el grupo Mano Negra, a través de las tácticas que Méndez caracteriza como interculturalidad popularsubalterna; nomadismo descentrado y bricolaje dialógico entre diversos estilos, que dará lugar a creaciones abiertas.

De la world music es relevante tener en cuenta lo que, a partir de Said, indica Méndez Rubio sobre la construcción de una visión orientalista que, al fin y al cabo, reduce la problemática en la que se encuentran dichos grupos subalternos; de algún modo, aunque en un campo distinto, podríamos vincular esta cuestión a las reflexiones que Mabel Moraña (1998:6) realizó en "El boom del subalterno" respecto a la introducción de la subalternidad como producto dentro un mercado globalizado y cómo se produce la mediación entre la subalternidad y el emisor del mensaje.

En este sentido, podemos plantear un ejemplo, en la vertiente de la música electrónica, de cómo desde la industria del mundo occidental se aprovechan, con fines comerciales, las músicas subalternas, con sus melodías y estética, y nos muestran esa visión orientalista o exótica que saca provecho de la situación de subalternidad de ciertas comunidades para extraer réditos. Víctor Lenore en su libro Indies, Hipsters y gafapastas analiza el caso del discjockey Diplo, al que cataloga como "icono del saqueo blanco posmoderno", de quien nos indica que sus producciones se basan en la reutilización cercana al plagio de música popular subalterna procedente, por ejemplo, de las favelas, pero sin el debido reconocimiento a los artistas originales; así se refiere Lenore a su caso:

Su mensaje fue "mira, estoy con la gente, me mezclo con ellos en los bailes de la favela. Es una perspectiva de turista blanco con tarjeta de crédito (...) Diplo ofrece a la industria justamente lo que quiere: nuevos ritmos cada nueve meses, ya sea reguetón, kuduro angoleño, trap (...) Se ha convertido en el perfecto mediador que nos permite disfrutar de un sorbo de cultura del gueto separándolo de los problemas de sus habitantes (2014: 92-93).

Otra de las nuevas músicas es el hip-hop, de carácter subalterno y, fundamentalmente, de origen negro y urbano. El hip-hop no solo se compone de música, en su interior es comprendida como una cultura formada por cuatro elementos: el rap, el breakdance o bboying, el graffiti y el turntablism, de manera que se conjuga tanto música, como baile y la expresión artística de carácter gráfico. El autor indica que surge en las zonas periféricas de las grandes urbes estadounidenses y que se convierte en vía de expresión para personas que se encuentran en situación de exclusión o marginación; de esta manera, Méndez indica a partir de lo que Michel de Certeau llamó las tácticas del arte del débil, como la improvisación, la mezcla o la precariedad instrumental.

En el hip-hop encontramos una muestra clarividente de la relación entre música popular subalterna y la industria que representaba la banda de Moebius; a pesar de ser un estilo suburbano y localizado, ha conseguido traspasar fronteras y establecerse, a partir del año 2000, como un estilo a nivel internacional que la 
industria musical convirtió en moda, generando una tensión en su interior entre la vertiente más underground y la comercial o mainstream.

El caso del gangsta-rap sería un claro ejemplo de cómo se producen estas negociaciones entre lo popular y lo masivo, pues en el gangsta se concentra tanto el componente político de denuncia ante una sociedad racista y muestra de manera abierta su agresividad, violencia y machismo; ante esto, es importante considerar cómo un género como el gangsta que roza la políticamente incorrecto y que representa a la perfección la etiqueta del Parental Advisory consiguió un amplio nivel de ventas. Así pues, debemos tener en cuenta la importancia de una figura como Suge Knight, el fundador de un sello mítico en la escena gangsta, Death Row Records, que produjo discos ya clásicos en la escena del hip-hop de artistas como Dr.Dre (ex N.W.A), Tupac Shakur, Snoop Dogg o Nate Dogg. La violencia, las drogas y las armas fueron los exponentes de este estilo, lo cual también fue su talón de Aquiles, pues los tiroteos y las confrontaciones entre bandas de la costa este y oeste dieron lugar a asesinatos como los paradigmáticos de Tupac y de Biggie Smalls (Notorius B.I.G.)

Sin embargo, es importante tener en cuenta lo indicado por Méndez respecto a la capacidad del hip-hop para resistir a los mecanismos de la industria y mantener su componente político y transgresor en lo que califica como un cortocircuito. Así pues, su internacionalización como estilo no solo ha demostrado su éxito comercial, sino que también su capacidad de diálogo e integración con otras culturas y que además es un estilo que ofrece herramientas de expresión y construye una identificación entre jóvenes de cualquier parte del mundo.

Finalmente, Méndez Rubio nos ofrece algunos rasgos sobre la música electrónica y su auge desde finales del siglo XX hasta el siglo XXI, debido a los cambios culturales derivados de los avances tecnológicos y de las transformaciones en las formas de producción y recepción. Méndez Rubio destaca que la música electrónica se ha convertido en un espacio de cruce y de diálogo entre músicas y modalidades artísticas y una muestra de ello es el sampling, con el que se utilizan diversos fragmentos musicales o sonoros con el fin de construir una producción musical. El autor indica que sus orígenes son fruto del carácter subcultural y su mezcla con la vanguardia; como señala Méndez, este juego con la experimentalidad ya pudo observarse en las vanguardias musicales y en figuras como Stockhausen o el grupo alemán Kraftwerk a partir de los años 70 .

Es especialmente notable la consideración que realiza el autor sobre la ruptura que supone la música electrónica en la concepción tradicional de la obra y su autoría, en favor de una vertiente más colectiva que encontraría en el Dj lo que Méndez Rubio asemeja a una figura chamánica que acciona la corriente musical.

En conclusión, en Comunicación musical y cultura popular. Una introducción crítica encontramos una obra abierta, plural, que pretende construir diálogo y nos devuelve a la concepción de la música como práctica social; el estudio abre nuevas vías de investigación en torno a la música y a la cultura popular, ya que desde diversos planos de análisis trae al frente la necesidad de atender, por un lado, a las condiciones sociales en las que tienen lugar las músicas populares, y, por otro lado, a las relaciones de poder que establece la industria musical y cultural con las creaciones artísticas en su paso hacia lo masivo. En este sentido, este libro se constituye como herramienta que nos dota de medios para enfrentarnos, de manera crítica, a la utilización que realizan los medios de comunicación y la industria de las expresiones populares.

ANTONIO GARCÍA DEL RÍO

UNIVERSITAT DE VALÈNCIA tonyg.rio@hotmail.com 
Otras referencias:

Lenore, Víctor (2014): Indies, Hipsters y gafapastas, Madrid, Capitán Swing Libros.

Moraña, Mabel (1998): "El boom del subalterno" Teorías sin disciplina (latinoamericanismo, poscolonialidad y globalización en debate).

Springsteen, Bruce (2016): Born to run, Barcelona, Literatura Random House. 